\title{
POLÍTICA DE INDEXAÇÃO NO CONTEXTO DA BIBLIOTECA PÚBLICA: PESQUISA ETNOGRÁFICA COM OBSERVAÇÃO PARTICIPANTE E PROTOCOLO VERBAL INDIVIDUAL
}

Jéssica Beatriz Tolare

Bolsista de Iniciação Científica PIBIC/CNPq/UNESP - Universidade Estadual Paulista "Júlio de Mesquita Filho". E-mail: jtolare@gmail.com

Mariângela Spotti Lopes Fujita

Docente Permanente do Programa de Pós-Graduação em Ciência da Informação - PPGCI/UNESP - Universidade Estadual Paulista "Júlio de Mesquita Filho". E-mail: mariangela.fujita@unesp.br

\section{Roberta Cristina Dal'Evedove Tartarotti}

Doutoranda do Programa de Pós-Graduação em Ciência da Informação - PPGCI/UNESP - Universidade Estadual Paulista “Júlio de Mesquita Filho". E-mail: roberta_tartarotti@yahoo.com.br

\section{RESUMO}

Na área de Produção e Organização da Informação, a indexação de documentos é um dos processos mais importantes no tratamento da informação documentária. Como forma de contribuir com os estudos de política de indexação em bibliotecas públicas, considerando o contexto de produção e organização da informação e visando a compreensão dos procedimentos de indexação para que sua realização atenda às necessidades dos bibliotecários e dos usuários, o objetivo da pesquisa é investigar a existência dos procedimentos de indexação em bibliotecas públicas. Para isso, foi aplicado um questionário seguido de observação participante com Protocolo Verbal para observação do processo de catalogação e indexação na Bibliotecas Municipais das cidades de Marília, Araraquara, Campinas, no Estado de São Paulo e Belo Horizonte no Estado de Minas Gerais. Os resultados revelaram que nenhuma das instituições possuem política de indexação registrada e sistematizada em um manual, os bibliotecários sentem dificuldades por não terem capacitação para a tarefa de indexação e os sistemas de informação automatizados utilizados para o catálogo online, quando existentes, são limitados e falhos na recuperação. Conclui-se que nas bibliotecas públicas há necessidade de aprimoramento dos métodos para a prática e qualidade da indexação mediante instrução e formação adequada aos 
profissionais e, sobretudo, para a elaboração de política de indexação sistematizada em manuais de procedimentos que resolva, inclusive, o problema de sistemas de informação automatizados falhos.

PALAVRAS-CHAVE: Indexação. Política de Indexação. Bibliotecas Públicas.

INDEXING POLICY IN THE CONTEXT
OF THE PUBLIC LIBRARY:
ETHNOGRAPHIC RESEARCH WITH
PARTICIPANT OBSERVATION AND
VERBAL INDIVIDUAL PROTOCOL

\begin{abstract}
In the area of Production and Organization of Information, indexing of documents is one of the most important processes in the treatment of documentary information. As a way of contributing to indexing policy studies in public libraries, considering the context of information production and organization and aiming to understand the indexing procedures so that their fulfillment meets the needs of librarians and users, the research objective is to investigate the existence of indexing procedures in public libraries. For this, a questionnaire followed by participant observation with Verbal Protocol was used to observe the cataloging and indexing process in the Municipal Libraries of the cities of Marília, Araraquara, Campinas, in the State of São Paulo and Belo Horizonte in the State of Minas Gerais. The results revealed that none of the institutions have an indexing policy registered and systematized in a manual, librarians feel difficulties because they do not have the capacity to indexing, and the automated information systems used for the online catalog, when they exist, are limited and flawed recovery. It is concluded that in public libraries there is a need to improve methods for the practice and quality of indexing through instruction and training appropriate to professionals and, above all, to the elaboration of a systematized indexing policy in procedures manuals that even solves the problem of faulty automated information systems.
\end{abstract}

KEYWORDS: Indexing. Indexing policy. Public Libraries

\title{
1 INTRODUÇÃO
}

A indexação é considerada um dos processos mais importantes do tratamento da informação realizado em bibliotecas. Quando se pensa em indexação não se pode limitar apenas a construir um buscador, mas sim um mecanismo, uma maneira em que o bibliotecário consiga encontrar a informação para o usuário e que ele por si só consiga também encontrá-la.

Carneiro (1985) ressalta a importância de haver uma política de indexação dentro de uma unidade de informação e que ela deve ser interpretada como um guia para tomar decisões.

Com isso, as chances de o bibliotecário ter desvios para determinar qual o termo mais

Complexitas - Rev. Fil. Tem., Belém, v. 3, n.1 , p. 100-119, jan./jun. 2018 - ISSN: 2525-4154 
apropriado para fazer a representação documentária diminui drasticamente.

A política de indexação, segundo Carneiro (1985), deve ser interpretada como um guia para tomar as decisões dentro da biblioteca, para que seja padronizado e não ocorra desvios na hora de determinar qual o termo mais apropriado para fazer a representação documentária. Assim, quando o usuário for realizar a busca, o sistema consiga recuperar a informação.

A política de indexação representa um conjunto de procedimentos que um indexador deve realizar a fim de facilitar o esclarecimento dos sistemas de informação e usuários quanto à recuperação da informação registrada.

Há fatores que contribuem para que não haja uma política de indexação em bibliotecas, principalmente, nas públicas como a falta de recursos tantos profissionais quanto financeiros. Por isso, muitas delas não possuem nenhum procedimento de indexação, nem um sistema e nem uma definição dos elementos de política de indexação.

Gil Leiva, Rubi e Fujita (2008, p.240) apontam que "uma política de indexação insuficiente ou inexistente pode contribuir para a falta de sistematização dos procedimentos de indexação e das diretrizes a serem seguidas pelos bibliotecários durante a realização da indexação", assim, sendo ruim para a biblioteca e, principalmente, para o usuário.

A afirmação dos autores é de extrema importância, pois é o que define se o trabalho foi realmente bem executado ou não, principalmente, na hora em que o usuário tenta recuperar a informação. E por não haver tantos estudos e pesquisas na área, torna-se necessário discutir isso a fundo para que haja uma mudança e melhore o cenário atual.

Para analisar, observar, pesquisar e estudar o porquê há essa falta de uma indexação e uma política de indexação dentro das bibliotecas públicas foi realizado uma coleta de dados na Biblioteca Municipal de Marília, na Biblioteca Municipal de Araraquara, na Biblioteca Municipal de Campinas e na Biblioteca Estadual de Belo Horizonte, onde foram analisados, através do questionário online e da observação participante com o Protocolo Verbal, a possibilidade de haver elementos de política de indexação, como o indexador realizou esse processo de prática de indexação.

\section{A POLÍTICA DE INDEXAÇÃO E A BIBLIOTECA PÚBLICA}

Fujita e Silva (2004) vinculam historicamente a indexação com a elaboração de índices e conceitualmente com a análise de assunto dos conteúdos documentários. 
As autoras reforçam que a indexação ganhou forças a partir do momento em que aumentaram as publicações científicas e percebeu-se que era necessário criar mecanismos de controle bibliográfico e de organizar os documentos por assuntos. Todo esse processo surgiu em centros específicos e não no âmbito das bibliotecas tradicionais.

A United Nations Internation Scientific Information System (UNISIT) é um programa que está ligado à United Nation Education Scientific and Cultura Organization (UNESCO) e que define o termo indexação como "a ação de descrever e identificar um documento de acordo com seu assunto." (UNISIT, 1981, p. 84).

De acordo com Chaumier (1988), uma indexação realizada de forma inadequada acarreta 90\% de "ruídos" ou de "silêncio" na recuperação da informação, ou seja, quando o usuário realiza uma busca pela informação e se ela não foi indexada de forma adequada, ele não consegue recuperar essa informação que deseja, sendo assim, o resultado de sua busca apresenta "silêncio", não apresentam resultados.

Rubi (2009) ressalta que o processo de indexação é composto por diferentes etapas, contudo, ela varia de acordo com os autores. Cada autor aponta uma quantidade de processos diferentes: duas (UNISIT, 1981; CHAUMIER. 1986; LANCASTER, 2004); três (ABNT 12.676, 1992) e quatro (VAN SLYPE, 1991; ROBREDO, 2005).

Apesar de haver essa divergência quanto ao número de etapas da indexação, eles basicamente tratam das mesmas operações:

- Análise: que ocorre a leitura e segmentação do texto para identificação e seleção de conceitos;

- Síntese: construção do texto documentário com os conceitos selecionados. Está relacionada especificamente à elaboração de resumos;

- Representação: por meio de linguagens documentárias.

Fujita (2003), Dias e Naves (2007) falam que a leitura documentária é essencial, pois corresponde à primeira fase de abordagem do leitor indexador, que desencadeará o processo de análise de assunto do texto para identificação e seleção de conceitos. Por isso, a análise realizada pelo indexador se dá em dois momentos: o primeiro quando ele analisa o documento para inseri-lo em um sistema de recuperação e, o segundo, quando recebe um pedido de informação do usuário.

Entretanto, os autores ressaltam que a indexação possui problemas quanto a subjetividade. A seleção dos termos realizada pelo indexador baseia-se em conhecimentos adquiridos a partir 
da experiência de vida dele. Mas se uma instituição possui uma política de indexação estabelecida na qual o indexador atua, automaticamente a indexação será realizada através dos padrões estabelecidos, sendo assim, a subjetividade será amenizada.

Segundo Dias e Naves (2007, p.31), há necessidade em estabelecer uma política de indexação no processo de indexação, pois é "imprescindível na orientação da atividade do indexador. Contendo uma política bem definida, tendo em vista o perfil de seus usuários, o sistema de recuperação de informação apresenta maiores chances de eficácia no alcance de seus objetivos.” (DIAS; NAVES, 2007, p.31).

De acordo com Rubi (2004) a recuperação de um documento "é mais eficaz quando se proporciona a identificação de conceitos mais pertinentes ao seu conteúdo, produzindo uma correspondência precisa com o assunto pesquisado em índices”. Para que ocorra esse processo é necessário que a instituição adote uma política de indexação, pois ela será a norteadora de princípios e critérios que servirão como um guia para tomar decisões para otimizar os serviços e na racionalização dos processos e, principalmente, influenciará diretamente no trabalho do indexador durante a leitura documentária nesse processo de indexação. (RUBI, 2004)

Fujita (2016) ressalta que uma política de indexação pode ser determinada por diversos fatores em uma unidade de informação, variando desde a seleção de tipos de documento a serem indexados, procedimentos de análise e representação de assuntos, aspectos qualitativos da indexação como precisão, especificidade, exaustividade e revocação, instrumentos de controle de vocabulários tais como linguagens documentárias ou opção por trabalhar com linguagem natural até a avaliação da indexação pela consistência e pela recuperação. (FUJITA, p.15, 2016) Segundo Carneiro (1985, p.221), uma política de indexação:

\footnotetext{
"Deve servir como um guia para tomada de decisões, deve levar em conta os seguintes fatores: a) características e objetivos da organização, determinantes do tipo de serviço a ser oferecido; b) identificação dos usuários, para atendimento de suas necessidades de informação; c) recursos humanos, materiais e financeiros, que delimitam o funcionamento de um sistema de recuperação de informações."
}

Carneiro (1985, p.231) ressalta que há alguns elementos necessários e que devem ser considerados para elaborar de uma política de indexação:

1. Cobertura de assuntos, assuntos centrais e periféricos;

2. Seleção e aquisição dos documentos-fonte, extensão da cobertura do sistema em áreas de 
assunto de seu interesse e a qualidade dos documentos, incluídos no sistema;

3. Processo de indexação: abarca variáveis que influenciam o processo de recuperação da informação;

3.1 Nível de exaustividade (número de conceitos atribuídos ao documento durante a análise);

3.2 Nível de especificidade (nível hierárquico da representação do assunto durante a fase de tradução dos conceitos);

3.3 Escolha da linguagem (no momento da busca e na indexação dos documentos);

3.4 Capacidade de revocação e precisão do sistema (revocação é a capacidade do sistema de recuperar documentos pertinentes e precisão é a capacidade de evitar documentos inúteis);

4. Estratégia de busca, se o próprio usuário realizará a busca ou o especialista;

5. Tempo de resposta do sistema, quando o sistema recebe de um pedido de informação e o momento que ele fornece uma resposta satisfatória;

6. Formas de saída, como resposta de um sistema, os números de acesso referentes aos documentos, referências bibliográficas, resumos ou o texto completo dos documentos;

7. Avaliação do sistema, a determinação da satisfação dos usuários com o sistema.

Fujita (2003, p.102) considera que a política de indexação deve estar inserida em dois contextos complementares. Um sendo o contexto sociocognitivo do indexador: a política de indexação, as regras e procedimentos do manual de indexação, a linguagem documentária para a representação e mediação da linguagem e os interesses de busca do usuário. E o outro, o contexto físico de trabalho do indexador: sistema de informação.

O contexto sociocognitivo está relacionado com o conhecimento que o indexador possui a respeito da ferramenta de trabalho, ou seja, a política de indexação, as regras e os procedimentos do manual e indexação, linguagem documentária e a necessidade real do usuário. E o contexto físico de trabalho que é ter o conhecimento da missão, objetivos, visão e valores da biblioteca em que o indexador trabalha.

Gonçalves (2008) aponta que a política de indexação não é vista nas bibliotecas como uma ideia que tem como objetivo estabelecer diretrizes, critérios e prioridades no processo de indexação. Uma política deve ser pensada para suprir os interesses e necessidades dos usuários, facilitando o acesso, a recuperação e a disseminação da informação. No entanto, é necessário levar em consideração a realidade local, onde muitas instituições não possuem uma política de 
indexação regulamentada, principalmente no Brasil, onde as pesquisas na área, ainda, são escassas.

Bernardino e Suaiden (2011) introduzem que, no Brasil, é preciso discutir sobre a leitura e o livro. Consequentemente, é necessário falar sobre o papel da biblioteca pública na sociedade. Esse papel social é permeado pelo acesso e disponibilidade da informação ao público, pois, assim, é traçado um objetivo dessas instituições, que podem ser alçando através de projetos, principalmente, culturais que visem a disseminação da leitura e da informação.

A biblioteca pública é um elo entre a necessidade de informação de um membro da comunidade e o recurso informacional, que nela se encontra de forma organizada e à sua disposição. (FUNDAÇÃO BIBLIOTECA NACIONAL, 2010)

O Manifesto da UNESCO (IFLA, 1994) sustenta que os serviços da biblioteca pública devem ser oferecidos com base na igualdade de acesso para todos, sem distinção de idade, raça, sexo, religião, nacionalidade, língua ou condição social. Os serviços e materiais específicos devem ser postos à disposição dos usuários que, por qualquer razão, não possam utilizar os serviços e os materiais correntes como pessoas deficientes, hospitalizadas ou reclusas.

Mueller (1984) ressalta que no decorrer da história, as bibliotecas públicas tiveram como funções básicas a coleta, a conservação, a organização e a difusão de informações e tem buscado através dessa difusão do conhecimento, a produção de um bem social. Sendo assim, pode-se afirmar, que a função social da biblioteca pública necessita de um maior empenho e de constantes avaliações.

Segundo Santos (2014) a biblioteca pública brasileira não abriga em suas estruturas condições necessárias para atuar de maneira eficaz na Sociedade da Informação, mesmo sendo considerada um espaço de cultura e de conhecimento. Ainda falta há muita coisa que deve-se fazer para melhorar e suprir as necessidades dos usuários.

Santos (2014) aponta que é necessário a biblioteca pública conhecer seus usuários, elaborar estratégias consistentes no sentido de trazer a população usuária para dentro da biblioteca.

Jaramillo, Montoya Rios e Uribe-Tirado (2008) destaca a existência de três variáveis consideradas importantes para o trabalho da biblioteca:

- Variáveis Externas: estão relacionadas com os aspectos econômicos, políticos, culturais, sociais e educativos; 
- Variáveis Internas: estão relacionadas de acordo com cada organização, como a visão organizacional, os objetivos, a missão e as formas de avaliação;

- Variáveis Mistas: abordam aspectos particulares de cada setor da biblioteca e as relações de cada um com o ciclo de transferência da informação.

Hoffmann (2012) explica que as bibliotecas públicas devem possuir um processamento técnico adequado ao seu acervo, onde a catalogação e a indexação represente os conteúdos dos documentos, possibilitando a busca pela informação rápida e precisa quanto ao material solicitado pelo usuário. Contudo, devido à falta de estudos e pesquisas na área tornou-se extremamente essencial discutir a política de indexação para que sejam analisadas alternativas que provoquem uma mudança e melhora no cenário atual.

\section{METODOLOGIA}

A pesquisa empírica consistiu de duas fases: a primeira de coleta de dados com aplicação de questionários a catalogadores de bibliotecas públicas municipais; a segunda envolveu a coleta de dados de documentação das bibliotecas públicas selecionadas e observação participante com aplicação da técnica introspectiva do Protocolo Verbal para observar a cognição e metacognição de bibliotecários durante a tarefa de indexação.

O questionário, elaborado por Fujita (2010, p.31), foi baseado em estudos teóricos sobre a indexação, elaboração da política de indexação e práticas de indexação com o objetivo de "verificar se os profissionais fazem a indexação e se adotam uma política de indexação e manual de indexação." O questionário é composto de vinte perguntas, organizadas em cinco categorias divididas em cinco categorias:

1. Dados Gerais da Instituição: Questões 1, 2, 3, 4, 5 e 6;

2. Prática da Indexação ou Catalogação de Assuntos: Questões 7, 7.1, 8, 9 e 10;

3. Qualidade da Indexação: Questões 11, 12, 13, 14 e 15;

4. Ferramentas para a Indexação ou Catalogação de Assuntos: Questões 16, 17 e 18;

5. Avaliação da Indexação ou Catalogação de Assuntos: Questões 19 e 20.

Para a aplicação do questionário foi realizado contato com os responsáveis das bibliotecas, a fim de promover apresentação e familiarização com a pesquisa, explicando seus objetivos: realizar estudo teórico sobre a indexação e a política de indexação em Organização e Representação do Conhecimento. O envio dos questionários foi realizado por correio eletrônico. 
As bibliotecas públicas municipais das cidades de Marília, Araraquara, Campinas do Estado de São Paulo e a biblioteca Estadual de Belo Horizonte do Estado de Minas Gerais foram escolhidas para a segunda com base nas respostas aos questionários.

Com fundamentação em artigo de Fujita e Santos (2010), foi aplicada a metodologia de Observação Participante com a técnica do Protocolo Verbal Individual para realizar a segunda fase da pesquisa que consistiu de um roteiro, elaborado por Santos (2011), composto de quatro passos:

Primeiro passo: conversa com o catalogador/indexador. Coleta de manuais e documentos para análise.

Segundo passo: aplicação do método do Protocolo Verbal no processo de catalogação de assunto/indexação de um livro.

Terceiro passo: elaboração de questões a partir das respostas obtidas no questionário da observação participante para a entrevista retrospectiva, a fim de sanar as dúvidas existentes.

Quarto passo: escolha de mais um ou dois funcionários para a entrevista retrospectiva.

A técnica de observação participante integra a pesquisa etnográfica assim como o Protocolo Verbal Individual. A pesquisa etnográfica tem como objetivo a descoberta de novas relações e de novas formas de entendimento da realidade a partir da observação e visão dos participantes sobre os significados dos resultados obtidos em sua prática cotidiana, para isso utiliza as técnicas de observação participante, entrevista e análise da entrevista pelo pesquisador com base nos aspectos observados e resultados obtidos de estudos teóricos, bem como análise da documentação, que se organizam em três etapas: 1) exploração que consiste na seleção dos problemas, do local e os primeiros contatos com o campo de estudo; 2) decisão, ou a busca dos dados para compreensão e interpretação do fenômeno; e 3) explicação da realidade, pela análise de todo o processo vivenciado pelo pesquisador, através dos relatos dos profissionais sobre a atividade desenvolvida (MAIA, 2007).

O Protocolo Verbal é uma técnica introspectiva adequada para a coleta de dados com os bibliotecários catalogadores, possibilitando a observação de suas estratégias durante a catalogação de assuntos. Esse método consiste em que a pessoa responsável pela catalogação explicite em "voz alta" todos os procedimentos durante a realização de uma determinada tarefa em tempo real enquanto o pesquisador grava com a autorização do catalogador.

Segundo Fujita e Cervantes (2005), o Protocolo Verbal é, assim, o único procedimento 
que promove acesso direto ao processo mental decorrente das atividades realizadas pelo leitor. Por essa razão, é considerada a técnica do "pensar alto" como uma técnica introspectiva. Outras técnicas que revelam o resultado do procedimento após sua realização são de natureza retrospectiva.

A aplicação do Protocolo Verbal consistiu de um conjunto de procedimentos sistematizados em anteriores, durante e após a aplicação, adaptados de Nardi (1990) e Tartarotti (2014).

\subsection{PROCEDIMENTOS ANTERIORES À APLICAÇÃO DO PROTOCOLO VERBAL}

a) Definição do universo da pesquisa: três bibliotecas públicas municipais das cidades de Araraquara, Marília, Campinas do Estado de São Paulo e uma biblioteca Estadual de Belo Horizonte do Estado de Minas Gerais.

b) Seleção dos catalogadores: A aplicação da técnica do Protocolo Verbal Individual ocorreu com 4 bibliotecários que realizam a catalogação de assuntos na amostra de bibliotecas públicas, gerando quatro protocolos verbais.

c) Definição da tarefa: realizar a catalogação de assuntos de livros no catálogo de cada biblioteca pública para observação da atividade por meio do Protocolo Verbal Individual.

d) Seleção do texto-base: Os livros sem catalogação anterior foram escolhidos pelos próprios bibliotecários e catalogados durante a coleta de dados

e) Conversa informal com os catalogadores: Realizou-se um primeiro contato por e-mail com a direção das bibliotecas do universo de pesquisa para o agendamento de coleta de dados. Antes da aplicação do Protocolo Verbal foram mencionados os objetivos da pesquisa e sua importância para a política de indexação em bibliotecas públicas. Foi informado e esclarecido que cada catalogador seria identificado apenas pelo nome da biblioteca pública onde trabalha, mantendo, assim, o anonimato.

f) Familiarização dos catalogadores com a técnica do Protocolo Verbal: Os quatro catalogadores foram apresentados inicialmente à técnica do Protocolo Verbal e seus procedimentos. A pesquisadora instruiu os catalogadores sobre como deveriam proceder durante a aplicação do Protocolo Verbal em "Instruções aos sujeitos" (Anexo A), adaptado de Nardi (1993). Foi esclarecido aos catalogadores que é preciso "pensar alto" durante a catalogação e esquecer a presença da pesquisadora, que está presente apenas para lembrar que é preciso verbalizar e controlar o gravador. 


\subsection{PROCEDIMENTOS DURANTE A APLICAÇÃO DO PROTOCOLO VERBAL}

O Protocolo Verbal conhecido, também, como "Pensar Alto" (Think Aloud), surgiu na década de 1970 e foi utilizado no âmbito da Ciência da Informação em Recuperação da Informação. De acordo com Cervantes $(2004$, p. 86) "é uma técnica introspectiva de coleta de dados que consiste na verbalização dos pensamentos dos sujeitos".

a) Gravação do "pensar alto" dos catalogadores: a gravação da verbalização dos catalogadores foi realizada, utilizando-se de um aplicativo de gravação do celular da pesquisadora durante a catalogação de livros.

b) Entrevista retrospectiva (optativa): Apesar de a entrevista retrospectiva ser optativa, ainda sim é de extrema importância para contextualizar o ambiente da biblioteca e aprofundar as informaç̃oes que podem não ter ficado tão claras durante o Protocolo Verbal.

\subsection{PROCEDIMENTOS APÓS A APLICAÇÃO DO PROTOCOLO VERBAL}

a) Transcrição literal das gravações das falas dos catalogadores: A gravação de cada Protocolo Verbal Individual propiciou a transcrição literal das falas dos catalogadores com a preservação das identidades e sinalização com código para cada biblioteca pública.

b) Leitura detalhada para a construção de categorias de análise: a leitura das transcrições dos protocolos verbais foi realizada para identificar categorias de análise dos dados.

c) Construção das categorias de análise: a leitura das transcrições possibilitou a criação de duas categorias: uso de procedimentos de leitura documentária e o uso do manual de políticas de indexação, procedimentos e serviços durante a catalogação e indexação do livro.

d) Retorno aos dados para retirar trechos que exemplifiquem cada categoria de análise: Os protocolos verbais foram lidos novamente para retirar trechos que pudessem servir de exemplos para cada categoria de análise.

Exemplos de transcrições de Protocolos Verbais:

Categoria 1 - Uso de procedimentos de leitura documentária para localizar no livro partes internas e externas pré-textuais e textuais, como capa, folha de rosto, introdução, etc.

A catalogadora leu a sinopse contida na orelha do livro. Segundo ela, quando não encontra, pesquisa na internet para saber do que o livro trata. Partindo disso, ela tenta encontrar termos que são mais adequados ao livro. 
Geralmente eu pego o começo, as orelhas, e dou uma pesquisada na internet, pra ver do que se trata o livro. Geralmente na Livraria Cultura eles dão um resumo do livro pra falar do que se trata, entendeu? Para a gente não errar muito longe. Mas isso nos livros mais antigos, nos livros mais novos, já vem bem uma catalogação legal. (Biblioteca Municipal de Marília)

Categoria 2 - Uso do manual de política de indexação, procedimentos e serviços durante a catalogação e indexação do livro

A biblioteca não possuiu nenhum manual de política de indexação e nem de procedimentos, apesar de demonstrar interesse em criar um futuramente.

Então, nós não criamos isso ainda. Até nós começamos a criar, porque a biblioteca nunca teve um manual, de serviço não. Aí o que que nós temos aqui, uma indexação de artigos de jornais ou, às vezes, até de revistas, as meninas acabam xerocando. Mas é mais jornais, que nós chamamos de pastas de recortes, que são essas pastas aqui. Por exemplo, sai um assunto aí de jornal, sobre alimentos transgênicos. Então elas leem o jornal, depois que passou o dia e grifam o assunto que interessam, aí quando acabam o mês, elas pegam esses jornais que elas ficharam, elas recortam o artigo, fazem isso aqui... ai elas colam nesse sulfitem indicam o jornal, a data e onde ele estará inserido dentro desse fichário. Essas pastas de recortes possuem os assuntos. Então se pesquisar o termo no programa, ele vai mostrar essas matérias também. (Biblioteca Municipal de Araraquara)

\section{RESULTADOS E DISCUSSÃO}

A apresentação dos resultados é uma síntese dos quatro itens de análise conforme metodologia: análise das respostas do questionário; análise da documentação das bibliotecas; análise da observação da indexação de livros com protocolo verbal individual; e, análise da entrevista com o catalogador.

Em termos gerais, após analisar cada biblioteca, é necessário ressaltar que há uma falta de recursos humanos e financeiros na maioria das bibliotecas, prejudicando o funcionamento delas que é precário. E por elas atenderem um grande público de pessoas de quase todas as idades é preciso haver maiores investimentos e atenção.

As quatro bibliotecas não possuem nenhuma política de indexação e três delas não possuem manual de procedimentos. Reflexo dessa situação é o fato de três bibliotecas não possuírem grau de especificidade definido para a determinação de assuntos. Cada catalogador e/ou indexador realiza da maneira que achar mais adequada sem exaustividade, especificidade e atribuição da quantidade de termos não tem delimitação precisa.

A falta de formação e treinamento dos profissionais que realizam a catalogação e indexação é prejudicial para a biblioteca e para o usuário, pois, se há dúvidas, tem que consultar 
um bibliotecário. E se a indexação não é feita de uma forma bom, o usuário não consegue recuperar a informação.

Os sistemas de informação automatizados utilizados por três bibliotecas são falhos e limitados o que prejudica os profissionais que não conseguem realizar o trabalho com precisão. Um dos sistemas obriga o profissional a preencher todos os campos, o que nem sempre é necessário.

Os profissionais que realizam a indexação na Biblioteca Municipal de Marília não são bibliotecários e, apesar de não possuírem capacitação contínua, trabalham há muito tempo e possuem a experiência. Mesmo havendo processos que desconhecem, eles tentam fazer da forma que acham melhor e quando há dúvidas consultam as bibliotecárias responsáveis.

A Biblioteca Municipal de Marília conta apenas com uma bibliotecária formada em Biblioteconomia, ocupando o cargo de bibliotecária-chefe. Quem realiza o processo de catalogação e indexação são profissionais, que apesar de não serem formados na área, atuavam nessa área há muitos anos.

A indexação era realizada em um software próprio, que foi interligado com a Web. Depois trocou-se pelo BibLivre, que é um software livre, gratuito e mais simples de ser utilizado. Contudo, tanto o primeiro, quanto o segundo é falho e limita o profissional obrigandoo a preencher campos, que muitas vezes não tem necessidade, como por exemplo, na catalogação e indexação de um livro de contos, o BibLivre não permite colocar todos os diferentes autores de contos nas observações, para depois fazer a remissiva e recuperar a informação na hora de buscar, que seria o ideal. Então é feito uma adaptação, e nos assuntos é colocado todos os nomes de autores, para que na hora que for pesquisar, conseguir encontrar um conto que está no meio do livro.

A Biblioteca não possui nenhum manual de indexação e nem uma política de indexação e, por isso, acaba havendo subjetividade na hora de catalogar e indexar o livro, gerando conflitos que poderiam ser evitados se houve uma política ou um manual de procedimentos adequados, prejudicando, principalmente, o usuário, que não consegue recuperar e nem acessar a informação como deveria.

A Biblioteca Municipal de Araraquara possui quatro bibliotecárias formadas na área e três auxiliares de biblioteca. Os profissionais bibliotecários têm formação na área e, por isso, acabam possuindo uma capacidade maior de conseguir indexar os livros. Possuem a 
preocupação com o usuário, mesmo não tendo contato e, mesmo com poucos recursos e tendo que lidar com a falta de verbas na biblioteca, os profissionais se preocupam em levar a informação para toda a comunidade.

Os bibliotecários realizam a catalogação e a indexação em um sistema criado especialmente para eles por um programador da cidade. A Biblioteca não possui manual de procedimentos, nem manual de indexação e nem de política de indexação. Eles realizam esses procedimentos da melhor forma que acharam possível, tentando obter o mínimo de subjetividade possível para que o usuário consiga recuperar a informação, mesmo assim, é perceptível os problemas que o sistema tem na hora de procurar a informação.

A Biblioteca Municipal de Campinas tem 5 bibliotecas municipais, incluindo uma central. Há uma sede separada especialmente para o processamento técnico específico do material. Apesar de haver três bibliotecárias formadas na área trabalhando especificamente no processamento técnico, a falta de recursos torna o trabalho muito precário, pois há uma entrada de livros muito alta, mas não há funcionários suficientes para atender toda essa demanda.

As bibliotecárias realizam a catalogação a mão em fichas e mandam para as bibliotecas que ficariam com os livros para inserir no sistema do catálogo de bibliotecas. Das cinco bibliotecas, três possuem um sistema semi-informatizado, enquanto as outras duas ainda trabalham apenas com as fichas catalográficas. Inexiste política de indexação e manual de indexação e, mesmo sendo apenas três bibliotecárias que trabalham nesse setor de processamento técnico separado, realizam o trabalho da maneira que acreditam que beneficiará o usuário e o trabalho do bibliotecário, sem seguir uma padronização. Um exemplo disso é a atualização da Classificação Decimal de Dewey (CDD) feita a mão, riscando as palavras, passando corretivo e escrevendo por cima as palavras que foram atualizadas. Segundo as bibliotecárias, isso ocorre devido à alta demanda de trabalho, a falta de verbas para comprar um sistema bom, materiais necessários e de pessoas para realizar esse trabalho.

A Biblioteca Estadual de Belo Horizonte, por outro lado, possui recursos mensais e, sendo assim, há sempre novos materiais chegando. Possuem a CDD atualizada, manual de procedimentos e um sistema de informação automatizado pago. Contudo, eles alegaram que mesmo com recursos financeiros existe uma alta demanda de serviço que, muitas vezes, não conseguem realizar.

Outro ponto importante é que o bibliotecário responsável pela catalogação e indexação 
processa o livro com termos mais gerais, pois antes do livro ir para o acervo passa pela mão do bibliotecário de referência que, por sua vez, realiza a indexação de forma aprofundada com termos mais específicos, justamente por ter contato com o usuário e ter uma ideia melhor do que pensa e por ter acesso ao vocabulário controlado da biblioteca, o que garante que ele consiga fazer uma boa indexação.

Na Biblioteca Estadual de Belo Horizonte encontraram-se três bibliotecários formados na área trabalhando especificamente no processamento técnico. Eles realizam a catalogação de assunto de forma geral, sempre que possível importam os registros de outras bases de dados.

Os bibliotecários alegaram que devido a grande demanda de material para tombar, o tempo acaba sendo escasso. Por isso, segundo eles, eles tentam realizar o trabalho de forma mais rápida possível. Eles utilizam a CDD atualizada e sua base é a do Pergamum, um sistema criado pela PUC-PR. A Biblioteca possui um manual de procedimentos, que de acordo com eles, é um documento com as leis que a biblioteca criou e tem que seguir na hora de realizar o processamento técnico.

\section{CONSIDERAÇÕES FINAIS}

A falta de recursos e atenção por parte gestão municipal e estadual é grave porque inviabiliza e compromete o atendimento de toda a comunidade pela biblioteca que não tem investimentos para a compra de livros e outros materiais essenciais à pesquisa e ao lazer. Devido à falta de incentivo e divulgação, muitas comunidades acabam desconhecendo a existência da própria biblioteca que poderiam fazer uso para aumentar o conhecimento e ter acesso à informação essencial para o pleno desenvolvimento como cidadãos.

Esses problemas sociais e econômicos são extremamente graves e precisam de atenção, mas uma forma de minimizar o problema é, justamente, melhorar a busca e recuperação da informação tanto para o usuário quanto para o bibliotecário mediante a indexação. Imbuídos de todos os aspectos dessa realidade adversa, os bibliotecários devem se emponderar de suas obrigações profissionais e elaborar a política de indexação que tornará exequível a tarefa de indexação para a adequada representação dos conteúdos documentários que vise o aprimoramento da recuperação da informação.

Tomamos como exemplo a decisão da Biblioteca Estadual de Belo Horizonte que decidiu pelo bibliotecário de referência para realizar a indexação. O bibliotecário de referência é 
o que tem maior contato com o usuário, consegue saber, ter uma ideia do que pensa e como buscaria essa informação, ao mesmo tempo que tem acesso ao vocabulário controlado da linguagem de indexação, com o qual pode indexar melhor do que um bibliotecário que só trabalha no processamento técnico e não possui contato com o usuário. Dessa forma, consegue combinar o que o usuário está pensando e o que buscaria no sistema com a linguagem de indexação da biblioteca.

Há pontos considerados pelos profissionais de indexação que deveria melhorar ou, até mesmo, mudar, tal como a falta de profissionais formados na área ou profissionais que não receberam cursos de capacitações que dependem, muitas vezes, apenas do auxílio de um bibliotecário-chefe como forma de consulta. O trabalho que esses profissionais desenvolvem tem como base a experiência de anos exercendo aquela mesma função, onde os indexadores realizam a indexação de maneira própria, que melhor lhe convém e, como consequência, tendo problemas com a subjetividade, causadora de "ruídos" que prejudicarão o usuário na busca e a recuperação da informação pela falta de precisão.

Outro ponto é a falta de verba, que seria necessária para viabilizar essas capacitações, cursos, implementar políticas, manual de procedimentos e, até mesmo, comprar sistemas que possam suprir as necessidades da biblioteca, principalmente, se a biblioteca possui um sistema que limita o profissional indexador no preenchimento de campos de informação. Alguns sistemas de informação automatizados são considerados falhos e, em alguns casos, obsoletos.

A biblioteca necessita elaborar um manual de procedimentos de indexação e um manual de política de indexação, pois, assim, os profissionais responsáveis pelo setor realizariam a catalogação e a indexação de forma padronizada, com o mínimo possível de subjetividade. Ambos manuais são de extrema importância, já que cada um possui a responsabilidade de atender uma comunidade ampla em vários aspectos, como por exemplo, de crianças até idosos. A elaboração da política depende tão somente da análise, discussão e planejamento por parte do indexador acerca das variáveis existentes no contexto profissional que o cerca, ou seja, a infraestrutura física, financeira e de recursos humanos e a comunidade usuária para a definição de elementos, processo e linguagem de indexação adequados.

A política de indexação é uma ferramenta extremamente importante e de grande utilidade para as bibliotecas. Serve como um guia para tomar as decisões dentro da biblioteca, de forma que evite a subjetividade na representação documentária para melhorar a busca e a recuperação da informação, mas, sobretudo, propõe a sistematização de todas as condutas Complexitas - Rev. Fil. Tem., Belém, v. 3, n.1 , p. 100-119, jan./jun. 2018 - ISSN: 2525-4154 
referentes aos elementos, processo e uso de linguagens de indexação.

\section{REFERÊNCIAS BIBLIOGRÁFICAS}

ABNT. NBR 12676: métodos para análise de documentos - determinação de seus assuntos e seleção de termos de indexação. Rio de Janeiro, 1992. p. 1-4. Disponível em $<$ https://edisciplinas.usp.br/pluginfile.p hp/372910/mod_resource/content/1/Nor ma\%20Brasilena\%20Indizacion\%20Isi doro\%20Gil\%20Leiva.pdf >. Acesso em: 29 ago 2018.

BERNARDINO, M. C. R.; SUAIDEN, E. J. O papel social da biblioteca pública na interação entre informação e conhecimento no contexto da Ciência da Informação. Perspectivas em Ciência da Informação, Brasília, v.16, n. 4, p.29-41, out/dez 2011. Disponível em: <http://portaldeperiodicos.eci.ufmg.br/i ndex.php/pci/article/view/1257/970>.

Acesso em: 29 ago 2018.

CARNEIRO, M. V. Diretrizes para uma politica de indexação. Revista da Escola de Biblioteconomia da UFMG, Belo Horizonte, v. 14, n.2, p.221-241, set. 1985. Disponível em: <http://www.brapci.inf.br/v/a/2649>.

Acesso em: 29 Ago. 2018.

CERVANTES, Brígida Maria Nogueira. Contribuição para a terminologia do processo de inteligência competitiva: estudo teórico e metodológico. 2004. 183 f. Dissertação (Mestra em Ciência da Informação, Unesp, Marília, 2004. Disponível em: <https://repositorio.unesp.br/bitstream/h andle/11449/93723/cervantes_bmn_me _mar_prot.pdf?sequence $=1$ \&is Allowed =y>. Acesso em: 29 ago. 2018.

CHAUMIER, J. Indexação: conceitos, etapas $e$ instrumentos. Revista Brasileira de Biblioteconomia e Documentação, São Paulo, v.12, n. 1/2, p. 63-79, jan/jun. 1988. Disponível em: <http://www.brapci.inf.br/v/a/11407>. Acesso em: 29 Ago. 2018.

DIAS; E. W.; NAVES, M. M. L. Análise de assunto: teoria e prática. Brasília, Thesaurus, 2007

FUJITA, M. S. L. A identificação de conceitos no processo de análise de assunto para indexação. Revista Digital de Biblioteconomia e Ciência da Informação, Campinas, v.1, n. 1, jul. 2003. Disponível em < https://periodicos.sbu.unicamp.br/ojs/in dex.php/rdbci/article/view/2089 >. Acesso em 29 ago 2018.

FUJITA, M. S. L. $O$ contexto profissional do indexador no ensino de indexação. Encontros Bibli: Revista Eletrônica de Biblioteconomia e Ciência da Informação, v. 15, p. 91-104, 2010. Disponível em < http://www.brapci.inf.br/v/a/9303>. Acesso em: 29 Ago. 2018.

FUJITA, M. S. L. (Org.) Política de indexação para bibliotecas: elaboração, avaliação e implantação. São Paulo: Cultura Acadêmica, 2016. Disponível em < https://www.marilia.unesp.br/Home/Pu blicacoes/politicas-de-indexacao-parabibliotecas_ebook.pdf >. Acesso em 29 ago 2018.

FUJITA, M. S. L; CERVANTES, B. M. N. Abordagem Cognitiva do Protocolo Verbal na confirmação de Termos para a Construção de Linguagem Documentária em Inteligência competitiva. In: VALENTIM, M. L. P. (Org.). Métodos qualitativos de pesquisa em Ciência da Informação. São Paulo: Polis, 2005.

FUJITA, M. S. L.; SANTOS, L. B. P. A indexação de livros por catalogadores com uso do modelo de leitura documentária: observação com

Complexitas - Rev. Fil. Tem., Belém, v. 3, n.1 , p. 100-119, jan./jun. 2018 - ISSN: 2525-4154 
protocolo verbal. In: XXII Congresso de Iniciação Científica da UNESP, 2010 .

FUNDAÇÃO

BIBLIOTECA

NACIONAL. Coordenadoria do

Sistema Nacional de Bibliotecas

Públicas. Bibliotecas Públicas:

princípios e diretrizes. Rio de Janeiro, 2010. $160 \mathrm{p}$.

GIL LEIVA, I.; RUBI, M. P.; FUJITA, M. S. L. Consistência na indexação em bibliotecas universitárias brasileiras. Transinformação [online]. v . 20, n. 3, $2008 . \quad$ Disponível em: https://repositorio.unesp.br/handle/1144 9/10578. Acesso em: 30-08-2018

GONÇALVES, M. C. A indexação em catálogo online em biblioteca universitária na percepção do usuário integrante de grupo de pesquisa: uma contribuição ao desenvolvimento de uma política de indexação na rede de bibliotecas da UNESP, (Dissertação) $2008 . \quad$ Disponível em $<$ https://www.marilia.unesp.br/Home/P os-

Graduacao/CienciadaInformacao/Disser tacoes/goncalves_mc_me_mar.pdf >. Acesso em 29 ago 2018.

HOFFMANN, P. Análise da indexação em bibliotecas públicas municipais da microrregião de Florianópolis - Santa Catarina. 2012. 44f. Trabalho de Conclusão de Curso (Graduação em Biblioteconomia) - Centro de Ciências da Educação, Universidade Federal de Santa Catarina, Florianópolis, 2012. Disponível em< https://repositorio.ufsc.br/handle/12345 6789/98619 >. Acesso em: 29 ago 2018.

IFLA. UNESCO. Manifesto $d a$ IFLA/UNESCO sobre bibliotecas públicas. 1994. Disponível em <http://archive.ifla.org/VII/s8/unesco/p ort.htm> Acesso em 1 agos. 2017.
JARAMILLO, O.; MONTOYA RIOS, M. URIBE TIRADO, A. La biblioteca pública y su gestión: em el contexto de la sociedade de la información. Buenos Aires: Alfagrama, 2008.

LANCASTER, F. W. Indexação $e$ resumos: teoria e prática. 2 ed. Brasília: Briquet de Lemos, 2004.

MAIA, G. Z. A. Pesquisa etnográfica e estudo de caso. In: MACHADO, L. M. M., MAIA, G. Z. A., LABEGALINI, A. C. F. B. Pesquisa em educação: passo a passo. Marília: Edições $\mathrm{M}_{3} \mathrm{~T}, 2007$. p.83-94.

MUELLER, S. P. M. Bibliotecas $e$ sociedade: evolução da interpretação de função e papéis da biblioteca. Revista da Escola de Biblioteconomia da UFMG, v. 13, n. 1, p. 7-54, 1984. Disponível em: <http://www.brapci.inf.br/v/a/2698>. Acesso em: 29 Ago. 2018

NARDI, M.I.A. As Expressões Metafóricas na compreensão de texto escrito em Língua Estrangeira. 1993. 260f. Dissertação (Mestrado em . PUCS. Paulo. 1993

NARDI, M. I. A. A metáfora e a prática de leitura como evento social: instrumentos do pensar a Biblioteconomia do futuro. 1999. $272 \mathrm{f}$. Tese (Doutorado em Linguística Aplicada e Estudos da Linguagem) Pontifícia Universidade Católica, São Paulo, 1999.

ROBREDO, J. Documentação de hoje e de amanhã: uma abordagem revisitada contemporânea da Ciência da Informação e de suas aplicações biblioteconômicas, documentárias, arquivísticas e museológicas. 4 ed. 
Brasília: [Autor], 2005. 409 p.

RUBI, M. P. A política de indexação na perspectiva do conhecimento organizacional. 2004. 135 f. Dissertação (Mestrado em Ciência da Informação) - Faculdade de Filosofia e Ciências, Universidade Estadual Paulista, Marília, 2004. Disponível em: https://repositorio.unesp.br/handle/1144 9/93688. Acesso em: 30-08-2018.

RUBI, M. P. Os princípios da política de indexação na análise de assuntos para catalogação: especificidade, exaustividade, revocação e precisão na perspectiva dos catalogadores $\mathrm{e}$ usuários. In: FUJITA, M. S. L. (Org.). A indexação de livros: a percepção de catalogadores e usuários de bibliotecas universitárias. Um estudo de observação do contexto sociocognitivo com protocolos verbais. São Paulo: Cultura Acadêmica, 2009. p. 83-93. Disponível em: https://repositorio.unesp.br/handle/1144 9/109109. Acesso em: 30-08-2018

SANTOS, L. B. P. Política de indexação em bibliotecas universitárias: estudo diagnóstico na região de Marília. Marília-SP: Faculdade de Filosofia e Ciências, 2011 (Trabalho de Conclusão de Curso).

TARTAROTTI, R. C. D. E. Atuação Bibliotecária no tratamento temático da informação em unidades informacionais: um estudo comparativo qualitativo-quantitativo. 2014. $277 \mathrm{f}$. Dissertação (Mestrado) Ciência da Informação, UFSCar, São Carlos, 2014. Disponível em <https://repositorio.ufscar.br/bitstream/ handle/ufscar/1140/6320.pdf?sequence =1>. Acesso em: 29 ago. 2018.

VAN SLYPE, G. V. Lenguajes de Indización: concepción, construcción y utilización em los sistemas documentales. Trad. do francês por Pedro Hípola e Félix de Moya. Madrid: Salamanca: Fundacion Germán Sánchez Ruipérez; Madrid: Pirámide, 1991. 200 p. (Biblioteca del Libro).

UNISIST. Princípios de indexação. Revista Escola de Biblioteconomia da UFMG, v. 10, n.1, mar.1981. 


\section{Anexo A}

\section{INSTRUÇÕES AOS SUJEITOS SOBRE A TÉCNICA DO "PENSAR ALTO” OU PROTOCOLO VERBAL (Adaptado de Nardi, 1993)}

O que vamos fazer agora é uma atividade de familiarização com a técnica de coleta de dados que será usada em nossa pesquisa.

Tudo que você tem a fazer é ler o texto da mesma maneira que você costuma ler um texto para indexação. É muito simples e natural.

Durante toda leitura você precisa "pensar alto". Tente imaginar você sozinho num recinto lendo um texto para indexação. Em situações como essa, já não lhe ocorreu começar a falar espontaneamente em voz alta, exteriorizando seus raciocínios, seus mecanismos mentais para conseguir compreender? Neste processo, o indivíduo "pensa em voz alta" verbalizando espontânea e quase inconscientemente seus pensamentos, questionamentos, suas buscas para eventuais problemas de compreensão, sua maneira singular de extrair significado de um texto.

Um exemplo bastante claro de exteriorização do pensamento durante a realização de uma tarefa (e que ocorre com a maioria das pessoas) é o "pensar alto" espontâneo durante a realização de um problema matemático.

Dá prá você ter uma idéia de como funciona essa técnica? Corresponde à verbalização de sua fala interna, seu pensamento.

Agora, a tarefa que você vai realizar é a leitura do texto que vai lhe ser apresentado... E, por favor, lembre-se de que é preciso "pensar alto" durante toda a leitura.

Você provavelmente encontrará passagens muito claras e fáceis de compreender, outras poderão lhe obrigar a uma "paradinha" para pensar um pouco mais... Tudo depende do seu próprio estilo.

Lembre-se, que nesses momentos de parada para pensar um pouco mais ou resolver algum problema, você deve tentar exteriorizar tudo que passar pela sua cabeça.

Se em algum momento da leitura, você achar difícil falar e pensar simultaneamente, você poderá fornecer uma explicação de como você compreendeu uma determinada passagem ou de como você buscou a solução para um problema de compreensão.

Na medida do possível, tente fazer esforços para "pensar alto" durante o seu processo de leitura. É um processo único em que falar é pensar.

Tente esquecer a presença da pesquisadora. Ela estará presente apenas para lembrar-lhe que é preciso "pensar alto" o tempo todo. Tente agir tão naturalmente quanto possível, como se você estivesse só.

Atente apenas para a tarefa que você deve realizar.

TOLARE; J.B.; FUJITA; M.S.L.; TARTAROTTI; R.C.D. Política de Indexação no Contexto da Biblioteca Pública: Pesquisa Etnográfica com Observação Participante e Protocolo Verbal Individual. Complexitas - Rev. Fil. Tem. Belém, v. 3, n. 1, p. 100-119, jan./jun. 2018. Disponível em: $<$ http://www.periodicos.ufpa.br/index.php/complexitas/article/view/6638>. Acesso em: 20 de fevereiro de 2019. 